\title{
Freedom of Religious Belief and People with Disabilities: Evidence from India
}

Around the world, people with disabilities can be the most marginalised in society. Having a disability and being a member of a religious minority or an excluded social group can compound the reasons why some people find themselves on the outskirts of social systems which normally provide financial and moral support and a sense of identity and belonging. A recent study from India found that identity markers such as religion, caste and gender can exacerbate the exclusion already experienced by people with disabilities. Taking deliberate steps to strengthen the social inclusion of people with disabilities who also come from minority religious groups and socioeconomically marginalised backgrounds can help them fulfil their potential to fully and effectively participate in society on an equal basis with others, and strengthen community ties, making the society in which they live more inclusive.

\section{Key messages}

- Discrimination based on factors including faith, disability, class, and gender is still prevalent in society.

- People with disabilities who are also affiliated to a minority religion can experience exacerbated marginalisation and social exclusion because of the intersection of those two identities. It can contribute to overlapping layers of marginalisation that are intertwined.

- One coping strategy to avoid discrimination is for people to disguise certain aspects of their identity such as their religious affiliation. They could face financial or personal safety repercussions if some of these facets of their identity are exposed.

- Measures aimed at reducing the number of people with disabilities who experience poverty achieve limited success if they are explicitly - or implicitly - only open to people from dominant religions or classes.

- Such measures should take into account the overlapping nature of marginalisation and exclusion between different experiences of discrimination and inequality, and how these can have a cumulative impact on people's poverty and wellbeing.

\section{Context}

Approximately 15 per cent of the world's population experience some form of disability, which includes those who have long-term physical, mental, intellectual or sensory impairments which in interaction with various barriers may hinder their full and effective participation in




society on an equal basis with others (WHO and World Bank 2011). Despite a number of international human rights frameworks enshrining disability inclusion rights, there are still many countries around the world where people with disabilities are among the most marginalised. They are generally poorer than their non-disabled peers and have less access to education, health care, employment, income, justice, social support, and civic involvement, and are more likely to experience multiple forms of poverty. With regards to responses and action to improve disability inclusion, not enough attention is paid to intersecting forms of discrimination. While some important and relevant frameworks, such as the Convention on the Rights of People with Disabilities, make reference to the multiple or aggravated forms of discrimination on the basis of religion and other factors people with disabilities face, the operationalisation of these frameworks remains inadequate in many contexts. This results in people with disabilities who belong to religious minorities continuing to face discrimination and compounded marginalisation.

Article 18 of the UN Universal Declaration of Human Rights (1948) enshrines the right to freedom of thought, conscience and religion; declaring that 'this right includes freedom to change his religion or belief, and freedom, either alone or in community with others and in public or private, to manifest his religion or belief in teaching, practice, worship and observance'. Many national constitutions guarantee - to varying degrees - the freedom to believe and to worship, and to live free of discrimination (including on the grounds of religion or belief). And yet millions of people around the world suffer from encroachments of this right on a regular basis. In countries where there is a dominant religion, members of other faiths are sometimes treated as secondary citizens and can face prejudice, discrimination and outright persecution. Religious affiliation, along with factors such as ethnicity, gender, and social class, can intersect with disability to compound the social exclusion of people with disabilities from their communities and result in inequalities being experienced.

\section{Case study: evidence from India}

In India, the prevalence of disability is 2.2 per cent according to the 2011 census, but data from the World Health Survey suggests it is as much as 24.9 per cent. Disability is more prevalent in rural areas and among members of Scheduled Castes and Scheduled Tribes. India is a signatory to the UN Convention on the Rights of Persons with Disabilities and passed a law enshrining the rights of people with disabilities in 2016. However, people with disabilities continue to face marginalisation in education, employment, mobility, and other significant life areas. Because of the common perception in India that disability is retribution for past karma, it is often regarded as being linked to sin. This can lead to people with disabilities either being treated with pity and charity or with violence and ridicule. When they are included in society, it is often done in a tokenistic way. More often than not, they are subject to negligence, segregation, and deprivation.

People with disabilities are not solely defined by their disability. Indeed, they may have diverse identities, including a religious identity. In India, religious affiliation (especially to a minority religion) along
"Millions of people around the world suffer from encroachments [on their right to freedom of thought, conscience, and religion]" 
with factors such as ethnicity, gender, and social class, can intersect with disability to compound the social exclusion of people with disabilities and exacerbate their experiences of inequality.

Whilst some 80 per cent of Indians identify as Hindu, India is home to other religious groups including Muslims, Christians, Sikhs, Jains, Buddhists and Zoroastrians. Throughout India's long history, these minorities have experienced both periods of social integration and harmony and periods of discrimination, alienation and violence. A recent rise in Hindu nationalism, spear-headed by the ruling Hindu nationalist Bharatiya Janata Party (BJP), has led to an increase in hate speech and/or communal violence against members of religious minorities in the last decade. This political populism has trapped religious minorities in a downward spiral of exclusion, disadvantage and socioeconomic deprivation. Policies designed to address poverty among religious minorities have had limited impact because they have not addressed underlying socioeconomic inequalities.

Dalit is a political identity which covers social groups identified as Scheduled Castes, at the bottom of India's ancient caste hierarchy.

\section{Methodology note}

India was selected as the focus country for this research because of its unique religious history and current sociopolitical situation. Case studies were gathered from 15 participants (three women and 12 men) in Chennai between July and September 2020. Eleven were Christian (six Catholic, five different types of Protestant), and four were Muslim. Ten had a physical impairment, four had visual impairment, and one participant was deaf-blind. Eight of the participants were Dalit and seven were non-Dalit. The researchers had hoped to speak to a larger and more diverse group, including Sikhs, Buddhists, Jains and people of no religion. However, the Covid-19 pandemic resulted in many of the institutions in Chennai through which they had hoped to meet participants being closed. Other potential interviewees chose not to participate in face-to-face interviews due to the risks associated with Covid-19.

\section{Data collected using the 'river of life' and narrative interviews}

Participants were invited to give an account of their life history using the 'river of life' method, following by a narrative interview. The major events and milestones in their lives, as featured along a 'river of life', revealed the ways participants evaluated their experiences and the people, places and events significant to them. The narrative

\section{Note about the researchers}

This research was undertaken by three researchers (two male and one female). Two Europeans based in the UK (with no significant involvement in organised religion) and a middle-class Dalit Catholic Indian. While the researchers recognise interviews were designed to draw on the interviewees' own experiences by inviting participants to describe experiences they have had. The introductory questions included one focused on experiences of disadvantage that may have been experienced as a person with a disability and as a result of being a member of a religious community.

their own positionality and the potential impact that aspects of their identity may have had on the analysis, they aimed to conduct the research in a fair and openminded way from a neutral stance. 
According to the 2011 census, Dalits make up 16.6 per cent of the Indian population. They are twice as likely to be poor, unemployed and illiterate as non-Dalits. They are also more likely to have disabilities due to poor living conditions, increased risks of illness, and poor nutrition among other factors. Dalits who have disabilities experience barriers to accessing public resources due to their disability and social status. Dalit women are at additional risk of sexual violence, which further enforces their subordinate social position. Dalit women with disabilities who are victims of abuse may struggle to access justice because their legal rights are often not recognised. Despite some efforts to address caste-based inequality, there lacks the political will to address the deep-seated discrimination Dalits face.

\section{Key findings}

The study found that religious affiliation, caste and disability all have the potential to impair a person's opportunities for education, work and marriage. Despite various legal and human rights frameworks at the national and international level that aim to prevent marginalisation, discrimination based on disability, faith, caste, and/or gender is still prevalent in India. Even where there were efforts to provide additional support to people with disabilities, for example training and employment for people with disabilities, discrimination still occurred on the grounds of religion or caste. In some cases, it is the consequences of discrimination which increase exclusion of people with disabilities. One participant for example, notes that 'In my office I have been discriminated [against] basically based on my disability, then on my being a Christian and then for being a Dalit'.

\section{Experiences of discrimination, abuse and exclusion}

Participants described experiences of both verbal and physical abuse, discrimination and exclusion from both the wider community and those within their own families or faith communities. These experiences were sometimes based on their disability or their religious affiliation, or both, and this gives a glimpse of how inequalities overlap and intersect in relation to different aspects of people's identities.

\section{Employment and state benefits}

Here, experiences of discrimination and exclusion tended to be in relation to participants' religious affiliation rather than their disability, for example:

- Dalit participants described additional barriers they face, as a result of also being from a religious minority as well as a social excluded caste. For example, Christian Dalit participants described how they had missed out on employment opportunities offered to Hindu Dalits as a result of being Christian.

- One participant, who considered themselves to be a Christian, is 'officially' a Dalit Hindu (on paper) which has entitled them to a government job, but 'if the government comes to know about my being a member of a Christian church, I may be taken out of the state benefits that I enjoy now as a Dalit Hindu'.
"[I]t is the consequences of discrimination [including on the grounds of religion or caste] which increase exclusion of people with disabilities" 
- Another Dalit Christian participant said 'had I been a Hindu Dalit, I would have received a lot of government loans and advances, I would have put my children in better schools'.

Society

Here, experiences of discrimination and exclusion are both in relation to religious affiliation and disability:

- Unprovoked assaults: a blind Muslim participant described his beard being grabbed in the street and his cap being snatched, while a visually-impaired Christian participant was assaulted on account of carrying a Bible and was accused of proselytising.

- Several participants described how inaccessible public transport was, and how the indifference from passers-by in the street made travelling to and holding down work difficult.

- Access to housing: one participant mentioned that 'we have been denied rented houses when we revealed that we are Christians' and felt this is also tied to the association of Christians with Dalits, which, coupled with their disability, led to the 'belief that we will not be able to pay rent in time'.

- Another participant who was involved in building a small church shared how local Hindus verbally abused them, stole their construction materials, and 'even excreted inside our building'.

- Many participants struggled to access education, either because decisions taken by the school ('I was denied an admission into a local Christian school that I was entitled to just because of the reason that I am disabled') or by their parents, whilst bullying by other pupils was a common experience among those who were allowed to attend a school. Additionally, accessibility was particularly challenging for the participants with physical impairments.

- Traders targeted by hired thugs: one participant described how, since the BJP Hindu nationalist party has been in government, Hindu competitors have organised a syndicate against Muslim traders like them and tried to usurp business opportunities from them, including through hooliganism perpetrated through goondas or hired thugs. The participant claimed that the goondas are often paid by local police to destabilise small businesses owned by Muslims.

\section{Families}

Here, experiences of discrimination and exclusion tended to be in relation to participants' disability rather than their religious affiliation, except for in instances of conversion:

- Some people with disabilities have had traumatic experiences of abuse and abandonment from some of their family members, including extended family. For example, one participant described how, when they were a child, their mother abandoned them in an orphanage, despite both their parents being alive - 'I was discriminated against by my own mother; I was handed over to an orphanage without my father's knowledge'. 
- Another was forced as a child by their parents to work for seven years as a servant in a relative's home, exposing them to mistreatment and restricting their education.

- Some participants said their lives had been restricted by their family's over-protectiveness; for example, one Muslim said their parents removed them from school when they went blind for fear they would suffer at school.

- One participant's Hindu biological father tied them up when he left the house due to the interest a pastor was taking in them and his fear that the pastor would convert them to Christianity. Another converted to Christianity in secret and 'years later when [their Hindu family] came to know about this, they were much upset. I felt I became a stranger inside home.'

\section{Faith communities}

Here experiences of discrimination and exclusion are mixed sometimes participants were discriminated against on the basis of their disability by their own faith community whilst welcomed into other faith communities, whereas in other examples, they experienced discrimination as a result of belonging to a different denomination but in the same faith community.

- A visually impaired pastor was driven out of the church he'd helped to set up and verbally abused by a few members citing his blindness as the reason he could not run a growing church.

- A Catholic participant with a physical disability described how when floods hit Chennai, he and his wife, who also has a disability, could not access the aid his church offered to poor families because they were unable to collect it from the church and the church officials did not make alternative arrangements for them despite being aware of their disabilities.

- A visually impaired Muslim participant described how Imams at their mosque did not help him participate in daily prayers or weekly worship, which left him feeling bitter towards both the mosque and himself, while a Christian with a physical disability described how, although their congregation wanted to include them, prayer meetings were often held in inaccessible locations such as high-rise buildings without lifts.

- A Protestant Christian described being bullied in their Catholic secondary school for belonging to a different denomination whereas a Catholic participant who'd had negative experiences of disability exclusion within their religious community, attended a Protestant school for persons with disabilities, which 'did an excellent job of inclusion by providing me the basic schooling'.

\section{Hiding their identities as a coping strategy}

Some participants said they felt it was necessary to disguise aspects of their identity to avoid discrimination. For example: one participant was a Dalit whose religion was listed as Hindu on his identity papers. As a Hindu Dalit he was entitled to certain state benefits, including a government job. He has joined a church but not notified the government, 
because he fears that if he did, he could lose his job and his financial stability. Another Christian Dalit hides their Dalit status in church for fear of missing out on opportunities offered them in the parish.

\section{Women's experiences}

Women from religious minorities are vulnerable to specific forms of violence and abuse. A recently published CREID report describes the particular vulnerability of poor women from religious minorities "when women are poor and belong to religious minorities in settings where religious "otherisation" is prevalent, they experience power and/or powerlessness in unique ways'. In India, Dalit women with a disability are also at heightened risk of sexual violence because of their community's low social position and because of superstitious beliefs held about them. Dalit Christian women are therefore trebly vulnerable. And yet they may struggle to access justice due to their marginalisation and an insufficient recognition of their legal rights.

\section{Single-issue interventions and policies do not necessarily address compound inequalities}

While some interventions and schemes are in place to overcome marginalisation, such initiatives often only focus on one aspect of identity (for example, having a disability) and they can be undermined by other forms of discrimination (for example, belonging to a religious minority). In relation to government schemes which support people with disabilities into jobs, one participant who had registered with the scheme had been so far unsuccessful, said this because they were a Christian Dalit, whereas they knew Hindus who had been successful. This example highlights how efforts to address only one source of exclusion at a time have only limited success.

\section{Benefits of social inclusion and specialised assistance}

Some participants had experienced social inclusion and specialised assistance from family members, friends, religious communities, or schools for people with disabilities that were run by other faiths than their own. They related how friends and family had fought to get them a school place, taken them to religious services, helped them start a business, or helped them find a partner. As a result, they felt accepted and their confidence increased. It also led to a strengthening of community ties, and to people with disabilities contributing in a meaningful way to society and realising their potential.

\section{Support from family and friends}

Several participants mentioned family members who had helped them get into school, attend religious services, set up a business or find a partner. One said a friend had enabled them to become independent by designing a tricycle for them.

\section{Support from faith communities}

Where religious communities had been inclusive in their distribution of roles and responsibilities, participants reported feeling more confident and of greater worth as a person. Participants spoke with gratitude of the lengths to which some congregations had gone to ensure they could participate in worship and social activities.
"Initiatives [which]

only focus on one aspect of identity (for example, having a disability)... can be undermined by other forms of discrimination (for example, belonging to a religious minority)" 


\section{Support from educational institutions}

Some participants who had attended faith-based schools for people with disabilities spoke positively of the inclusion they had experienced. One participant described how being included at school had given them moral strength and helped them to set goals and achieve them. One Muslim participant who attended a Bible College described how 'the college...provided ...special facilities to [help me] keep up...with other students and also [helped me] practise my religion...; for example, [buying] me a Quran with much bigger printed letters'.

\section{Specialised training}

Specialised training for people with disabilities can lead to increased self-worth as well as employability. Ironically, one participant said they were more skilled after they went blind and qualified for government training, because beforehand, poverty had cut short their education and limited them to unskilled work.

\section{Policy recommendations}

- Development policy and practice should recognise that people have multiple identities and that these can sometimes exacerbate exclusion, marginalistion and vulnerability, especially in contexts of intersecting inequalities which can have legal, social, economic and political impact.

- States must adhere to the international human rights frameworks that they have committed to, including the United Nations Universal Declaration of Human Rights and the Convention on the Rights of Persons with Disabilities, which both protect freedom of religious belief and the rights of people with disabilities. Non-state actors, such as businesses, religious bodies or private organisations, should not wait for state adherence to fulfil the principles of these human rights frameworks in their own practice.

- Interventions targeting one factor of people's identities - for example, being a woman or having disabilities - should consider the potential impact of other identity factors, such as religious affiliation or caste. Otherwise, there is the risk that the effectiveness of the intervention is negated by discrimination against other aspects of a person's identity.

- Where religious discrimination and inequality are prevalent, public and sometimes state-sanctioned, people will sometimes keep their religious identity private or secret which makes it harder to identify and potentially target disadvantaged groups.

- Exclusion and marginalisation can be experienced from within the community and it should not be assumed that discrimination against a wider group, such as members of a minority faith group, necessarily creates solidarity and inclusive practices within this group.

- Action is needed to ensure all religious activities become inclusive. Reasonable accommodation must be provided to ensure people with disabilities have the ability and freedom to participate in religion and practice their chosen religious faith.

"People have multiple identities and these can sometimes exacerbate exclusion marginalistion and vulnerability, especially in contexts of intersecting inequalities" 


\section{Further reading}

Dandona, R.; Pandey, A.; George, S.; Kumar, G. and Dandona, L. (2019)

'India's Disability Estimates: Limitations and Way Forward', PLoS ONE 14.9

Haq, R.; Klarsfeld, A.; Kornau, A. and Ngunjiri, F.W. (2020) 'Diversity in India: Addressing Caste, Disability and Gender', Equality, Diversity and Inclusion 39.6: 585-96

Shenoy, M. (2011) Persons With Disability and the India Labour Market: Challenges and Opportunities, Bangkok: ILO Regional Office for Asia and the Pacific

Tadros, M. (2020) Invisible Targets of Hatred: Socioeconomically Excluded Women from Religious Minority Backgrounds, CREID Working Paper 2, Brighton: Institute of Development Studies

Tadros, M. and Sabates-Wheeler, R. (2020) Inclusive Development: Beyond Need, Not Creed, CREID Working Paper 1, Brighton: Institute of Development Studies

Thompson, S.; Rohwerder, B. and Arockiasamy, C. (2021) Freedom of Religious Belief and People With Disabilities: A Case Study of People With Disabilities from Religious Minorities in Chennai, India, CREID Working Paper 7, Brighton: Institute of Development Studies,

DOI: 10.19088/CREID.2021.003

WHO World Report on Disability, Geneva: World Health Organization

\section{Credits}

This policy briefing draws on a paper by Stephen Thompson, Brigitte Rohwerder and Clement Arockiasamy, and was compiled by Abigail Frymann Rouch and edited by Emilie Wilson. It was produced as part of the Coalition for Religious Equality and Inclusive Development (CREID), a consortium funded by UK Aid from the UK government which provides research evidence and delivers practical programmes which aim to redress the impact of discrimination on the grounds of religion or belief, tackle poverty and exclusion, and promote people's wellbeing and empowerment.

The opinions expressed are those of the author and do not necessarily reflect the views or policies of IDS or the UK government.

CREID Policy Briefings are published by the Institute of Development Studies and aim to share key research findings and make practical recommendations for policymakers and donors.

(cc) BY This is an Open Access publication distributed under the terms of the Creative Commons Attribution 4.0 International licence (CC BY), which permits unrestricted use, distribution, and reproduction in any medium, provided the original authors and source are credited and any modifications or adaptations are indicated.

\section{DOI: 10.19088/CREID_2021.004}

\section{Institute of Development Studies, Brighton BN1 9RE, UK \\ $\mathrm{T}+44(0) 1273606261$ \\ $\mathrm{F}+44(0) 1273621202$ \\ E creid@ids.ac.uk \\ Wwww.ids.ac.uk/creid \\ T@CREID_Dev}

CREID partners
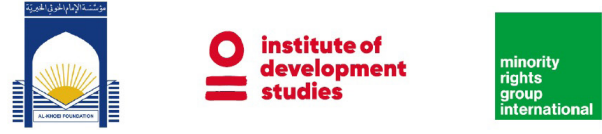